\title{
O SANTUÁRIO DE YAZILIKAYA: UM DEMARCADOR DA ETNICIDADE EM HATTI
}

\author{
Leonardo Candido Batista \\ Monica Selvatici
}

\section{RESUMO}

Esse trabalho tende a analisar os principais aspectos do santuário de Yakilizaya, esboçando como os hititas souberam ordenar diversas divindades em seu panteão. A sociedade em Hatti era muito diversificada culturalmente, e no campo religioso é visível como esses aspectos culturais se misturavam e iam se ressignificando através das relações entre os diversos povos que habitavam a região da Anatólia em meados do segundo milênio. O santuário de Yakilizaya, fora dos muros da capital Hattusa, é em sua essência mais geral uma procissão talhada em rocha de sessenta e quatro deuses, sendo na esquerda deuses, e na direita deusas. Considera-se que essa procissão segue uma ordem utilizada pelos hurritas, sendo que ao longo da história dos hititas, principalmente em sua religião, houveram muitas adaptações de várias características religiosas de todo o Oriente Próximo, que é observado pelo inflado panteão do povo de Hatti, mostrando a flexibilidade desses em absorver outras culturas. Na religião hitita podemos observar como as fronteiras étnicas são flexíveis e tangíveis, aquelas diversas culturas que deram origem ao reino dos hititas no bronze tardio, eram interligadas uma a outra, alimentando e cimentando o que teria sido essa complexa sociedade.

Palavras-chave: Hititas; Yazilikaya; Etnicidade

\section{ALGUMAS CONSIDERAÇÕES SOBRE A RELIGIÃO HITITA}

O terreno acidentado do platô da Anatólia e do norte da Síria com varreduras de montanhas proporcionavam um tipo de adoração inanimada da natureza esse tipo de culto, como destaca Manfred Hutter (1997, p. 75) não só compreende componentes políticos e históricos, mas geográficos e climáticos eram importantes para a religião hitita: da alta Mesopotâmia e norte da Síria ao sudeste e centro da Anatólia, a agricultura e a vida econômica dependem das chuvas que fazem possível a cultivação. Como as pessoas dependem também dos fenômenos atmosféricos por viverem nessas diferentes áreas, elas também expressam suas crenças religiosas em um modo comparável. Portando não é possível explorar a religião hitita sem levar em consideração as tradições da Síria e da Mesopotâmia. Uma atenção especial é dada a cosmologias, calendários míticos, como o mito do deus-grão hurrita Kumarbi.

Os hititas souberam como apropriar a tradição mesopotâmica de colocar os deuses nos tratados com os outros estados, fizeram isso reformulando para o que agora seria o panteão dominante de sua religião:

\footnotetext{
"And whoever alters the words of this treaty tablet will transgress the oath. The Thousand Gods shall be aware (of the perpetrator, beginning with) the Storm-god of Heaven, the Sun-god of Heaven, the Stormgod of Hatti. the Sun-goddess of Arinna, Hebat of Kizzuwatna, Ishtar
} 


\title{
XI SEMINÁRIO DE PESQUISA EM CIÊNCIAS HUMANAS - SEPECH \\ Humanidades, Estado e desafios didático-científicos \\ Londrina, 27 a 29 de julho de 2016
}

of Alalah, Nikkal of Nubanni. and the Storm-god of Mount Hazzi" (Hittte Treaties/Divine Witness) ${ }^{1}$.

Os hititas foram hábeis na apropriação do discurso mesopotâmico, subvertendo o sentido original. E isso é muito visível quando é sublinhado as mil divindades, que se agruparam ao longo do tempo ao panteão hitita, lembrando sempre que ganhando formas diferentes:

\begin{abstract}
Ambas as listas de tratados e as orações apresentam virtualmente o panteão hitita, mas as listas de tratados são manifestamente uma compilação feita para esse propósito particular. $\mathrm{O}$ deus-sol está à frente da lista como o deus da justiça. Ele é quase uma réplica do acadiano Shamash. De qualquer forma, os deuses que ajudam o rei na batalha, por exemplo, não incluem o deus-sol. Aqui encontramos incontáveis vezes liderando a lista a deus-sol de Arinna e o deustempo de Hatti. É o deus-tempo, não o deus sol, que é representando concluindo o tratado com o deus-sol egípcio, em favor do Estado hitita, e ele era relacionado como o marido da deusa-sol de Arinna. Assim até o auge do império hitita, não havia uma singular unidade hierárquica de deuses (GURNEY, 1977, p.6).
\end{abstract}

A prática de remover as estátuas dos deuses locais de seus templos e leva-las aos do conquistador, mostrava a transferência desses deuses a um novo panteão. Eles não poderiam mais ser invocados pelos conquistados, o revestimento material na qual eles habitavam eram levados à outra localidade. O conquistador mostrava todo devido respeito e consideração à nova divindade. Na terra de Hatti eles retinham suas identidades individuais, até mesmo se eles fossem idênticos em função, característica e nome com deuses de outros territórios conquistados, ou deuses ali já estabelecidos. Havia uma plenitude de deuses da tempestade, deusas do Sol, Ishtares e equivalentes. Todos se tornavam membros da assembleia divina hitita, e eram meramente diferenciados colocando-se seus nomes e seus locais de origem. $\mathrm{O}$ resultado era um enorme complexo, não sistemático, e algumas vezes uma completa e confusa aglomeração de deidades na formação do panteão. Nesse aspecto os hititas foram relativamente além dos sistemáticos panteões do Egito e da Mesopotâmia. Eles tinham muito orgulho disso (BRYCE, 2002, p.136). É interessante observar, como aponta Bryce, que a capacidade de adotar diversas deidades não demonstra apenas a capacidade dos hititas de se expandir e conquistar povos. Não obstante além de tolerar, eles absorviam e assimilavam dentro da estrutura de sua própria cultura e sociedade elementos de culturas e sociedades que compunham a terra de Hatti.

Puduhepa, esposa de Hattusili III fez uma revisão de práticas religiosas e tradições por todo mundo hitita, e começou a racionalizar o panteão estabelecendo sincretismos entre as principais divindades, em outras palavras, identificando deuses hititas com seus homólogos hurritas. Trevor Bryce (2002, p. 137) fala que em certo ponto esses sincretismos visavam diminuir a multiplicidade de divindades parecidas no

${ }^{1} \mathrm{E}$ qualquer um que alterar as palavras desse tratado, irá violar o juramento. Os mil deuses devem estar cientes (do perpetrador, começando com) o deus-tempestade do paraíso, o deus-sol do paraíso, o deus-tempestade de Hatti, a deusa-sol de Arinna, Hebet de Kizzuwatna, Ishitar de Alalah, Nikkal de Nubanni, e o deus-tempestade do monte Hazzi (Tratados hititas/Testemunha divina). 


\section{SEMINÁRIO DE PESQUISA EM CIÊNCIAS HUMANAS - SEPECH \\ Humanidades, Estado e desafios didático-científicos \\ Londrina, 27 a 29 de julho de 2016}

panteão. Mas elas claramente refletiam o alto grau de hurritananização da cultura hitita. Isso se tornou particular no reino de Hattusili III, principalmente pela influência de sua esposa hurrita. Montanhas, rios e fontes eram habitadas ou identificadas como deuses ou espíritos. Como sabemos, terreno acidentado do platô da Anatólia e do norte da Síria com varreduras de montanhas proporcionavam esse tipo de adoração.

\section{YAZILIKAYA, E A PROCISSÃO DE SESSENTA E QUATRO DIVINDADES}

Um elemento fundamental para entendermos como os hititas absorveram tantos deuses em seu panteão, mostrando toda essa flexibilidade de fronteiras, e toda a mistura cultural ao longo de sua história é o santuário de Yazilikaya fora dos muros da capital Hattusa, que em sua essencial mais geral é uma procissão talhada em rocha de sessenta e quatro deuses, sendo a esquerda deuses, e a direita deusas. Harry Hoffner Jr (2006, p.133) fala que os relevos desse santuário mostram duas longas linhas de deuses e deusas que convergem em um ponto central, aonde o deus chefe, Teshub, e a deusa chefe, Hebat, olham um ao outro. $\mathrm{Na}$ face da rocha, exatamente oposta a esse ponto central, o escultor talhou a semelhança do único humano retratado na cena divina. A figura é a do rei Tudhaliya IV (1237-1209 a.C) vestindo os trajes do deus-sol e de pé sobre duas montanhas. A simetria da cena é notável: sendo que Tudhaliya, confronta o rei divido, Teshub, e sua rainha. As duas figuras masculinas dividem características significantes. Apesar do rei ser humano, como Teshub ele carrega a iconografia de deidade. Ele está vestido exatamente como o deus-sol, que aparece do lado esquerdo da procissão na mesma câmara. Como Teshub fica sobre duas montanhas deificadas, Tudhaliya também fica sobre duas montanhas, apesar de diferentemente das montanhas de Teshub, essas não são desenhadas antropomorficamente. Como Teshub é o rei da assembleia representado nas paredes da câmara, Tudhaliya é então o rei dos adoradores humanos que agrega na área central da câmara. Essa procissão de deidades é algo peculiar até para a arte hitita da época:

A separação em Yazilikaya de procissões de homens e mulheres, corresponde, como Emmanuel Laroche tem mostrado. Para uma ordem seguida pelos hurritas, e não pelos hititas, na lista de poderes sobrenaturais. Mas para ter arranjado os dois grupos nos dois lados da câmara, de tal modo que cada um avança em direção, e então as duas principais divindades que lideram seus cortejos, confronta-se e encontram-se uma a outra, é uma criação independente e original do artista. Ele era um escultor hitita, ou foi convocado pela corte de Hattusa do mundo hurrita? Não sabemos. Ainda como considerada sua realização, e como ela superou todas os outros desenhos esculturais contemporâneos conhecidos da Anatólia, é visto na combinação das suas procissões, do modo que as figuras que lideram pertencentes a uma e a mesma família de deuses. Para o panteão hurrita. Teshub é o principal deus, é o consorte de Hepat, a principal deusa, e Sharruma é o filho, que marcha imediatamente atrás de sua mãe. Essa tríade, então, no relevo central de Yazilikaya, conectam as suas procissões em um significante caminho (BITTEL, 1970. p. 97-98). 


\section{SEMINÁRIO DE PESQUISA EM CIÊNCIAS HUMANAS - SEPECH \\ Humanidades, Estado e desafios didático-científicos \\ Londrina, 27 a 29 de julho de 2016}

O lugar não deve ter sido escolhido de propósito, já que é um afloramento de rochas naturais criando câmaras de diferentes tamanhos, fora as fontes de água frescas que fluem, dando um aspecto harmonioso para os deuses. James Macqueen (1986, p. 123) fala que essa região por todo esse caráter deve ter sido um lugar de adoração muitos séculos antes do surgimento dos hititas. Além do mais as representações das divindades em Yazilikaya causam a impressão que ali é um lugar de encontro sagrado, como destaca Roger Chartier (2002, p.165) o efeito-representação do duplo sentido, de presentificação do ausente - ou do morto- e de auto-representação instituindo o tema de olhar no afeto e no sentido, a imagem é simultaneamente a instrumentalização da força, o meio da potência e sua e sua fundação em poder. Um duplo sentido, uma dupla função deste modo atribuídos à representação: tornar presente uma ausência, mas também exibir sua própria presença enquanto imagem e assim constituir aquele que a olha como sujeito que olha. Kurt Bittel (1970, p.98) fala que o escultor de Yazilikaya evidentemente tentou transmitir uma unidade para aqueles que não pudessem entender os nomes em hieróglifo - Tesub, Hepat, e Sharruma - mas tinha que depender de seu entendimento pela representação pictográfico. Para atender as necessidades dos deuses, os hititas estabeleceram processos formas elaboradas de sacrifícios. As oferendas eram caracterizadas por boa comida, bebidas como cerveja e vinho, e primícias dependendo da época do ano. Animais eram frequentemente sacrificados e seu sangue oferecido aos deuses. Billie Jean Collins (2007, p. 165) explica que as preparações do sacrifício começavam com a consagração do animal e a limpeza dos participantes, a imagem da divindade, e o espaço onde ocorreria o sacrifício. Uma liturgia poderia ser recitada e um incenso era queimado. $\mathrm{O}$ animal era trazido algumas vezes com muita fanfarra. Somente produtos de qualidade eram oferecidos à divindade. A substituição de um animal magricela por um saudável garantia uma retribuição divina. A procissão podia incluir cantores e músicos, como outras participantes do ritual, por exemplo, o cozinheiro. $\mathrm{O}$ momento do abate era usado uma faca especial. Depois do abate do animal, eram oferecidos a divindade o coração assado e o fígado. O cozinheiro pegava os restos e fazia um ensopado, que era divido entre os participantes. Assim começa a festa com comida e bebida. Nesse ponto o rei poderia "beber o deus", ou seja, brinda-lo, uma prática única aos hititas. Os deuses precisavam desfrutar de toda essa ostentação, como lembra Gary Beckman (1989, p. 102) as necessidades e os desejos dos deuses hititas eram concebidos como sendo similar aos nobres de Hatti. O templo do deus era simplesmente sua casa. Esses eram grandes estabelecimentos contendo armazéns e oficinas onde produtos necessários para o serviço divino eram feitos. Fora da cidade, existiam grandes extensões de terras cultivadas a serviço dos deuses em seus determinados templos.

Essa impregnação de deidades com características hurritas é marcante pela peculiaridade artística de Yalizikaya, o que torna esse santuário uma coisa única no mundo antigo. Ele é o exemplo esplêndido de como a divindade Iskur (nome do deus da tempestade em sumério) chegou ao mundo hitita (agora com uma camuflagem hurrita), e no final do Império hitita, a cultura material presenteia toda essa metamorfose nos relevos em rocha. Algo tão complexo não poderia ter sido mostrado de melhor forma, parecendo até proposital algo dessa magnitude. Mais do que o lado estético, Yalizikaya, podemos observar como as unidades e os limites culturais persiste, torando possível a compreensão de uma forma final de manutenção de fronteiras, como destaca Barth (2008, p. 196) situações de contato social entre pessoas de culturas diferentes também 


\section{SEMINÁRIO DE PESQUISA EM CIÊNCIAS HUMANAS - SEPECH \\ Humanidades, Estado e desafios didático-científicos \\ Londrina, 27 a 29 de julho de 2016}

são implicadas na manutenção da fronteira étnica: grupos étnicos persistem como unidades significativas apenas se implicarem marcadas diferenças no comportamento, isto é, diferenças culturais persistentes. Contudo, onde indivíduos de cultura diferente se interagem, pode-se esperar que tais diferenças se reduzissem, uma vez que a interação simultaneamente requer e cria uma congruência de códigos e valores - melhor dizendo, uma similaridade ou comunidade de cultura (BARTH, 2008, p. 196). Gurney (1977, p. 22) argumenta que na Kaluti de Teshub, Ea, o deus da lua, o deus sol, Astabi, e o deus "tutelar" do tipo KAL, são listados nessa ordem, e Ishtar-Sausga - a forma masculina dessa divindade - é incluída, embora em um momento posterior. Os deuses 41 e 40, entre Teshub e Ea devem ser de acordo com as listas dois do grupo que consistem nos irmãos de Teshub; Tasmisu e os deuses Suwaliyat e Kumarbi. Se Suwaliyat é meramente outro nome para Tasmisu como se pensou, não há mais nenhuma dificuldade aqui; a divindade número 41é "irmão" de Teshub o número 40 é Kumarbi. As duas pequenas garotas seguindo Sausga (número 37, e 36), ambas os nomes podem ser vistos no final em - tâ que devem ser suas assistentes Ninatta e Kulitta. É sugerido que os números 31 e 30 seja, Pirinkir e Hesui. Os dois sinais combinados em um único desenho com um par de homens touros, na qual não possuem nomes, podem ser Seri e Hurri. Os restantes são incertos, mas os números 17-13 são mostrados como deuses da montanha, e parecem serem rotulados como "montanhas divinas". Os doze corredores que se apresentam na parte posterior pode ser os "doze deuses da encruzilhada", um grupo uma vez mencionado em ligação com o deus do submundo Nergal. Na procissão feminina, os nomes e figuras estão bem danificados, sendo que existia originalmente vinte deusas seguindo Allanzu e a neta, mas uma foi totalmente obliterada, e pelo menos uma, mais provavelmente duas, foram cortadas e retiradas em outro lugar. Uma dessas foi encontrada na vila vizinha de Yekbas (GURNEY 1977, p. 23).

Essa procissão de divindades mostra-se como um fato intrínseco de como todas essas divindades tiveram um papel importante em Hatti. Deuses de diversas localidades e de diferentes culturas, estavam protegendo e guiando os hititas, todos em reconhecimento e adoração. Dessa maneira, podemos dizer que a etnicidade é esse fluxo constante de trocas e valias culturais, essas pertenças ganham novos atributos em um novo local, mas não chegam a perder suas funções básicas:

Assim a persistência de grupos étnicos em contato, implica não apenas critérios e sinais de identificação, mas igualmente uma estruturação da interação que permite a persistência das diferenças culturais. O traço organizacional que, segundo minha tese, deve ser encontrado em quaisquer relações interétnicas consiste em um conjunto sistemático de regras dirigindo os contatos interétnicos. Em qualquer vida social organizada, o que se torna relevante para a interação em qualquer situação social particular está prescrita (Goffman,1959) (BARTH, 2008, p.196).

Bittel (1970, p. 100) fala da gravura de Imamkulu, outro relevo com um padrão similar ao de Yazilikaya que uma das principais características a analisar os relevos de rocha como um todo, são as séries de figuras individuais e temas, combinados em uma procissão unificada de deidades masculinas e femininas, sendo isso sem precedentes na arte hitita antes de Yazilikaya, tanto quanto se possa julgar dos monumentos que restaram. Mas alguém se pergunta se os precursores de Yazikikaya devem ser vistos 


\section{SEMINÁRIO DE PESQUISA EM CIÊNCIAS HUMANAS - SEPECH \\ Humanidades, Estado e desafios didático-científicos \\ Londrina, 27 a 29 de julho de 2016}

como exclusivamente nas artes monumentais, ou talvez também em artes menores. É certo que divindades individuais, especialmente os deuses que lideram, foram representados como no século XVIII a.C. Isso é mostrado por uma pequena figura liderante de deuses com grandes chapéus, túnicas e cimitarras, na qual correspondem precisamente a uma série de deuses idênticos em Yazilikaya

Como vimos, as divindades em Hatti podiam ser adoradas em várias formas, além da convencional como em templos e santuários. Não é de se surpreender essa peculiaridade religioso do mundo hitita, se pegarmos o panorama cultural e étinico anatoliano do bronze tardio, podemos tecer todos esses contrastes culturais ali existentes em todas essas tradições religiosas. As representações dos deuses eram ambas antropomórficas (como representado em Yazalikaya), e antropozoomórfico (como na representação de touro do deus trovão). Um dado curioso é que muitas dessas imagens não chegaram até nós, sendo o santuário o mais profundo exemplo dessa expressão religiosa. É estranho pensar que não chegou muita coisa relacionada a estátuas de culto para o estudo da cultura material, já que os hititas possuíam, ou pelos menos consideravam várias divindades como protetoras. Uma explicação plausível para isso, seria as frágeis estruturas de madeira de Hatti, assim quando a capital foi queimada não sobraram muitas coisas, sendo que grandes perdas ocorreram, mas não seria de se estranhar que os hititas negligenciassem a produção de em massa de estátuas, devido à natureza muitas vezes inanimada de sua religião. Visando esse aspecto, Gurney (1977, p.25) entende que a maioria dessas imagens de culto no templo em forma humana foram uma inovação dos benefícios do rei, sendo que anteriormente a deidade era representada tanto como um símbolo como por uma estela, na qual a palavra hitita para isso é "pedra huwasi. A exceção é o deus do tempo/tempestade, que como sabemos era representado por um touro, ambos antes e depois do enriquecimento do templo. Em um lugar chamado Marash, existiam quadro divindades. Para Gary Beckman $(1989$, p.99) à partir do século XIII a.c, alguns esforços para sistematizar, e muitas divindades foram agrupadas no kaluti, em círculos de divindades masculinas e femininas nos baixos relevos de Yazilikaya, sendo significativo que apesar de sua iconografia fazer muitas dessas deidades imediatamente reconhecidas como membros de longa data do panteão hitita, seus selos hieróglifos são seus nomes em hurrita.

Assim segue o padrão das representações esculpidas em rochas em Yazilikaya, para Bittel (1970, p. 103) os relevos nas duas câmaras não diferem e estilo ou forma, sendo que está claro que elas pertencem a mesma convenção artística. De qualquer forma, as representações aparecem nas paredes em diferentes arranjos. $\mathrm{Na}$ câmara maior, temos uma procissão de deidades masculinas e femininas que se encontram na cena principal, onde as supremas divindades relacionadas a cada fileira se encontram face a face. Na câmara menor, encontramos relevos completos em si mesmos, isolados sem qualquer interconexão visível. Ao lado dos deuses há duas figuras de grandes reis hititas. Eles não são desenhados em uma forma individual, mas são estereotipados. Ambos os nomes são, de acordo com as inscrições em hieróglifo acompanhando-os, Tuthaliya, como já sabemos, acontecendo muitas vezes nas listas reais hititas, mas entre um grande número de nomes reais. A única posição desse nome particular em Yazilikaya, é enfatizado pelo cartucho isolado na câmara menor na qual contêm o nome de Tuthaliya (BITTEL, 1970, p.103). A importância do terreno rochoso da Anatólia foi essencial para o surgimento de santuários nessas regiões, além da importância e da adoração de fontes e montanhas como divindades. É o que Dirk Paul Mielke (2011, 


\section{SEMINÁRIO DE PESQUISA EM CIÊNCIAS HUMANAS - SEPECH \\ Humanidades, Estado e desafios didático-científicos \\ Londrina, 27 a 29 de julho de 2016}

p.153) chama a atenção, sendo os termos Hoyuk e cidade montanha frequentemente opostos, a fim de caracterizar as cidades hititas. A "cidade montanha" é normalmente apresentada como um tipo novo de assentamento resultando somente com a primeira aparição dos hititas, mas de qualquer forma essa classificação não é inteiramente adequada para descrever a peculiaridade das cidades hititas; muitos dos assentamentos conhecido através das evidências arqueológicas podem ser chamadas de "cidades montanhas", simplesmente por sua posição em colinas naturais dentro da paisagem montanhosa da Anatólia. Por outro lado, muitas delas são sitos de multi-períodos, e poderiam muito bem ser igualmente classificados como hoyuks. A verdadeira prática dessa classificação mencionada é para ver de preferência o fenômeno de uma política extensiva de assentamentos forçada pelos hititas no curso na qual novas cidades foram fundadas.

Yazilikaya, foi segundo Bittel (1970, p. 104) um lugar muito relacionado com manifestações de poderes divinos muito antes de ser provida de relevos, porém escavações em frente do complexo bruscamente antes da segunda guerra e em 1966, mostraram que esse lugar de adoração era mais que apenas um santuário a céu aberto. $\mathrm{O}$ grupo de rocha e as câmaras eram conectadas com construções arquitetônicas, na qual não mudaram o complexo rochoso fundamentalmente, fazendo parte de um expressivo precinto de culto. Aproximando-se do santuário via a estrada hitita processional, entrando uma primeira vez, encontra-se um grande e isolado propileu com escadas que levam até o terraço maior. Então através de um portão menor, alcança-se um pátio retangular ladeado de dois lados por salas pequenas de variados tamanhos. Portanto, é uma questão complicada pensar a forma as formas de adoração em Hatti como algo institucional organizado, a própria natureza religiosa pode muito bem ter contribuído com essas características, Para Paul Mielke (2011, p 169), deve-se ter em mente que os termos hititas para unidades funcionais necessariamente não correspondem para distintivos tipos de construção. Relacionado a esse problema, está a questão se templos ou construções de natureza cultual existiam naturalmente no complexo palaciano em Buyukkale. Baseado em textos, que refere a natureza de ações cultuais no palácio, muitas tentativas têm sido feitas para identificar estruturas escavadas como templos ou santuários. Okse (2011, p. 231) comenta que registro cuneiformes informam sobre rituais de evocação contra feitiçaria fora dos muros da cidade, em um rio ou fonte nas montanhas. A descrição desses rituais, indica que a câmara principal se assemelha ao palco para eles. Considera-se que uma dessas câmeras era usada para cultos aos ancestrais, especialmente para Tudhaliya IV. Podemos concluir que Yazilikaya fora uma construção peculiar, apesar de ser comum a construção de santuários a céu aberto em Hatti:

Assim, Yazilikayia, com toda sua elaboração arquitetônica, pelo menos no plano, começa a se assemelhar com os templos normais hititas, e embora seja certo que as câmaras de rocha nunca foram cobertas, mas estavam abertas para o céu. Mas ressonâncias recentes perto das fundações, mostram que essas similaridades têm definido limites. Os templos hititas, onde quer que os conheçamos - Bogazkoy, Huyuk, perto de Alaca ou na Cilicia - são distinguidos por uma muito sólida construção, especialmente por fundações que são cuidadosamente colocadas juntas. Em Yazilikaya, as construções, exceto pelo propileu, foram elevadas de maneiras descuidada. As 


\section{SEMINÁRIO DE PESQUISA EM CIÊNCIAS HUMANAS - SEPECH \\ Humanidades, Estado e desafios didático-científicos \\ Londrina, 27 a 29 de julho de 2016}

fundações dificilmente descem o leito de pedra, mas geralmente definido em escombro. As pedras, mesmo as peanhas visíveis das paredes, eram selecionadas casualmente. Algumas vezes as pedras eram reusadas de outras construções, e as articulações de blocos individuais geralmente não se encaixam propriamente. Portanto, é bastante evidente que aqui, diferente dos templos da cidade, alguns dos quais tinham muitos andares altos, aqui estamos falando de construções com apenas um andar. As leves construções na frente de Yazilikaya podem ter resistido duramente ao uso ritual atestado em um culto diário pelo um templo normal hitita. Pode-se imaginar, que o tipo de construção era determinado pelo propósito do complexo, e aquele santuário era usado somente ocasiões limitadas e especiais ao longo do ano (BITTEL, 1970, p. 107).

Observamos dessa maneira como o santuário de Yazilikaya mostra essa flexibilidade da religião hitita em absorver outras deidades. Esse é um monumento único, tanto no plano arquitetônico, quanto na forma de expressar o caráter religioso. A representação desse santuário, é um reflexo de toda a nossa discussão até aqui, ela nos brinda com toda essa amplitude étnica do que talvez fosse uma hurritalização do panteão hitita com Puduhepa, e uma de suas orações a deusa do sol de Arinna, mostram características desse sincretismo:

O Sun-goddess of Arinna, my lady, queen of all the lands! In Hatti you gave yourself the name Sun-goddess of Arinna, but the land which you made, that of the cedar, there you gave yourself the name Hebat. I, Puduhepa, am your long-time servant, a calf of your stable, a (corner)stone of your foundation. You picked me up, my lady, and Hattusili, your servant, to whom you married me, and he too was attached by destiny (lit. lot) to the Storm-god of Nerik, your beloved son. The place in which you, O Sun-goddess of Arinna, my lady, installed us, is the place of your beloved son, the Storm-god of Nerik (Prayer and Vow to the Sun-goddess of Arinna \$2 3-33).

Eriksen (1993, p. 50) considera que uma categoria étnica é consistente aplicação de rótulos mutuais de exclusividade étnica, sendo que essa rede adiciona canais, um grande acordo de interações ao longo das linhas étnicas. Quando membros de uma categoria étnica sentem que dividiram interesse, e desenvolvem um aparato organizacional para expressa-lo, sendo apropriado falar de associação étnica. O maior degrau de incorporação étnica é o da comunidade étnica. Esse tipo de coletividade tem, em adição as redes étnicas e divide uma organização política, um território com uma mais ou menos fronteira física permanente (ERIKSEN, 1993, p. 51).

2 Oh deusa sol de Arinna, minha senhora, rainha de todas as terras! Em Hatti, você deu a si mesma o nome de deusa sol de Arinna, mas a terra que você fez, aquela de cedro, lá você deu seu próprio nome de Hebat. Eu, Puduhepa, sou sua serva de longa data, uma vitela de seu estábulo, um pilar da sua fundação. Você me pegou, minha senhora, e Hattusili, seu servo, a quem você casou comigo, ele também foi ligado pelo destino (muito iluminado) pelo deus da tempestade de Nerik, seu filho amado. 0 lugar na qual você, Oh deusa sol de Arinna, minha senhora, nos colocou, é o lugar do seu amado filho, o deus da tempestade de Nerik (Oração e Voto para a deusa sol de Arinna §2 3-33) 


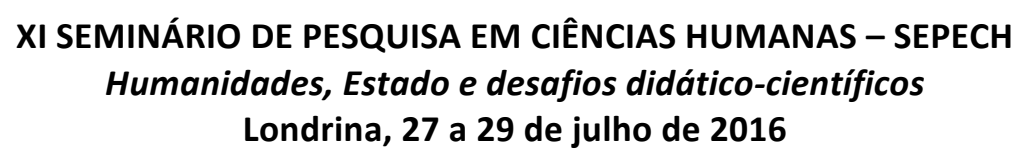

\section{CONCLUSÃO}

Os aspectos apresentados mostram como a religião em Hatti era flexível e sempre abraçava novas influências, isso se deve as diversas características de fronteiras étnicas existentes na Anatólia no Bronze Tardio. É um exagero levar ao pé da letra o próprio nome que os hititas se davam como "o povo dos mil deuses", mas não podemos esquecer que eles fizeram com maestria a assimilação de divindades de diversas partes do Oriente Próximo, sendo muito bem administrada como jogo político pelos soberanos de Hatti. O estudo da religião hitita traz uma luz sobre as composições étnicas existentes na Anatólia do segundo milênio, mostrando não uma religião homogênea e sistemática, mas sim aparatos simbólicos ressignificados, como ritos, orações, divindades, e em cada localidade do vasto reino hitita, elas muitas vezes funcionavam de formas diferentes, de acordo com a cultura local. Yazilikaya mostra como a flexibilidade das fronteiras étnicas tocaram o sistema religioso hitita, trazendo deuses de todo o Oriente Próximo, fazendo desse santuário uma obra única na História. Sua importância vai além dessa peculiaridade, é um retrato ainda vivo de como os hititas eram cuidadosos com suas mil divindades, rotulando e elaborando conceitos, explicações e tendências até mesmo para divindades de conceitos inanimados. Assim podemos, mesmo que muito pouco, observar a transculturação na esfera religiosa de Hatti, sempre aceitando novas divindades, e sempre tendo um espaço de adoração e importância.

\section{REFERÊNCIAS \\ FONTES}

BECKMAN, Gary. Hittite Diplomatic Texts. Atlanta: Scholars Press, 1996.

SINGER, Itamar. Hittite Prayers. Atlanta: Scholar Press, 2002.

\section{BIBLIOGRAFIA}

BARTH, Fredrick. In POUTIGNAT, Philippe \& STREIF-FENART (orgs). Teorias da Etnicidade. Seguido de Grupos Étnicos e suas Fronteiras de Fredrik Barth. São Paulo: Fundação Editora da UNESP, 2008.

BECKMAN, Gary.: The Religion of the Hittites. The Biblical Archaeologist, Vol. 52, No. 2/3, Reflections of a Late Bronze Age Empire:The Hittites (Jun. - Sep., 1989), pp. 98-108

BRYCE, Trevor. Live and Society in the Hittite World. Oxford: Oxford University Press, 2002.

CHARTIER, Roger. À Beira da Falésia: A História Entre Certezas e Inquietudes. Porto Alegre: Editora da Universidade UFRGS, 2002.

COLLINS, B.J. The Hittites and their World. Atlanta: Society of biblical literature, 2007. 
ERIKSEN, T. H. Ethnicity and Nationalism: Anthropological Perspectives. London: Pluto Press, 1993.

GURNEY, O.R. Some Aspects of Hittite Religion. Oxford: Oxford University Press, 1977.

HOFFNER, Harry A. Jr. The Royal Cult in Hatti. In: Beckman and Lewis (orgs). Text, Artifact, and Image: Revealing Ancient Israelite Religion. Providence: Society of Biblical Literature Press, 2006.

HUTTER, Manfred. Religion in Hittite Anatolia. Some Comments on "Volkert Haas: Geschichte der Hethitischen Religion. Numen International Review for the History of Religion. Vol. 44, No. 1 (Jan, 1997), pp. 74-90.

MACQUEEN, J.G. The Hittites and their Contemporaries in Asia Minor 2d edition. London: Thames and Hudson, 1986.

MIELKE, DIRK PAUL. Hittite Cities: Looking for a Concept In: GENS and MIELKE (orgs). Insights into Hittite History and Archeology. Leuven: Peeters, 2011.

ÖKSE. A. Tuba. Open-air Sanctuaries of the Hittites. In: Gens and Mielke (orgs). Insights into Hittite History and Archeology. Leuven: Peeters, 2011 